\title{
Neuronal Development and Migration in Explant Cultures of the Adult Canary Forebrain
}

\author{
Steven A. Goldman \\ Department of Neurology, Cornell University Medical College, New York, New York 10021
}

The vocal control nucleus (HVc) of the songbird forebrain undergoes neurogenesis in adulthood, as ventricular zone precursor cells divide, and their daughter cells migrate into the subjacent forebrain and differentiate into neurons. A procedure is now described by which the migration and development of these new neurons can be directly observed in vitro, in explant cultures of the adult canary forebrain. Cultured explants have yielded extensive outgrowth of new neurons from 2 neurogenic regions of the adult songbird brain: the HVC and its adjacent dorsomediocaudal neostriatum. Immunocytochemically identified neurons were determined by ${ }^{3} \mathrm{H}$-thymidine autoradiography to have been newly generated in vivo, in the days preceding explantation. These cells were immunoreactive for a variety of neuron-selective antigens, including MAP-1B, MAP-2, neuron-specific enolase, synaptic vesicle protein-2, N-CAM, and the tetanus toxin and A2B5 ligands. Combined immunostaining and autoradiography of cultures derived from HVcs exposed to ${ }^{3} \mathrm{H}$ thymidine in vivo revealed a population of newly generated, MAP-2 $/{ }^{3} \mathrm{H}$-thymidine-positive neurons.

The neurons identified in these adult explant outgrowths comprised new, recently generated postmitotic cells which had arisen in the neostriatal ventricular zone and were in the early stages of their parenchymal migration at the time of tissue explantation. Accordingly, nonneurogenic control regions, including the anterior hyperstriatum, cerebellum, and optic tectum, did not display neuronal outgrowth in culture. Only forebrain regions exhibiting neurogenesis in vivo manifested neuronal outgrowth and maturation in vitro.

The song control nucleus of the adult canary forebrain, $\mathrm{HVc}$ (hyperstriatum ventralis, pars caudale), exhibits a substantial degree of neuroplasticity in adulthood. This forebrain nucleus

\footnotetext{
Received Aug. 21, 1989; revised April 9, 1990; accepted April 25, 1990.

I am grateful to Drs. Elaine G. Diacumakos and Fernando Nottebohm for their advice and criticism. I note with particular sadness that Dr. Diacumakos passed away in June 1984, during the early stages of this work. She has been greatly missed.

I appreciate the assistance of Georgienne Bradley and Wendy Clarke in culture preparation and immunocytochemistry and Sarah Carson in photography. I thank the following individuals for their gift of antibodies: Dr. Itzhak Fischer, Eunice Shriver Center and Harvard Medical School (MAP-2, MAP-1B); Dr. Kay Fields Albert Einstein College of Medicine (A2B5 and tetanus); Dr. Kathleen Buckley, Harvard Medical School (SV-2); and Drs. Vance Lemmon, Case Western Rescrve Medical School, and Carl Lagenaur, University of Pittsburgh (1A6).

This project has been supported by the Y. Lila and G. Harold Mathers Foundation, as well as by NINDS Clinical Investigator Development Award K08 NS

01316. The author is a Cornell Scholar in Biomedical Science.

Correspondence should be addressed to Dr. Steven A. Goldman, Department of Neurology/A-579, Cornell University Medical College, 1300 York Avenue, New York, NY 10021.
}

Copyright (C) 1990 Society for Neuroscience $0270-6474 / 90 / 092931-09 \$ 03.00 / 0$ exhibits de novo neurogenesis in adulthood, with new neurons originating from neuronal precursor cells located in the adjacent ventricular epithelium (Goldman and Nottebohm, 1982, 1983). Precursor cell mitosis is followed by the directed migration of the nascent daughter neurons into the underlying $\mathrm{HV}_{\mathrm{c}}$, where they differentiate into neurons (Goldman, 1983; Goldman and Nottebohm, 1983; Alvarez-Buyulla and Nottebohm, 1988). These neurons become synaptically competent (Paton and Nottebohm, 1984; Burd and Nottebohm, 1985) and may serve primarily as interneurons within the song nucleus HVc (Paton et al., 1985), although some of the newly generated cells do project to HVc's target nucleus, robustus archistriatalis (RA; AlvarezBuyulla et al., 1988). This constant neuronal neoplasia entails an unceasing perturbation of the local cellular and neurochemical milieu, by which means the adult canary's song repertoire is continually modified and redesigned (Nottebohm, 1985).

The considerable degree of in vivo neuroplasticity within the adult canary $\mathrm{HVc}$ suggested both the feasibility and desirability of studying this region in vitro. Neuronal tissue culture has traditionally been limited to studies of the embryonic brain in vitro. Prior attempts at adult avian and mammalian CNS culture have been infrequent (Costero and Pomerat, 1951; Hogue, 1953; Geiger, 1958). Although several groups have maintained mammalian CNS explants in vitro (Kiernan and Petit, 1971; Kim et al., 1979; Messing and Kim, 1979), only from teleosts have adult CNS tissues been successfully cultured with in vitro neuritic and neuronal outgrowth (de Boni et al., 1976; Anderson and Waxman, 1985). The scarcity of work on the adult brain in tissue culture has been due largely to the putative inability of the adult CNS to adapt well to the in vitro environment. Nevertheless, it seemed likely that the adult songbird $\mathrm{HVc}$ might retain a capacity for substantial morphogenesis in vitro, in light of its significant in vivo plasticity. A procedure has therefore been developed by which explants of the adult passerine forebrain can be maintained for several weeks in vitro, under conditions in which ongoing neuronal migration and differentiation may proceed. By a combination of adult brain culture, ${ }^{3} \mathrm{H}$-thymidine autoradiography, and immunocytochemistry, we have identified in vitro those neurons newly generated in the adult $\mathrm{HVc}$ ventricular zone and have characterized the in vitro development of this unique neuronal subpopulation. Preliminary versions of various aspects of this work have been reported in abstract form (Goldman et al., 1982; Goldman and Diacumakos, 1984; Goldman and Clarke, 1989).

\section{Materials and Methods}

Culture preparation. Adult female canaries of both Wasserschlager and American Singer strains were anesthetized with Chloropent $(0.07 \mathrm{ml}$ 
i.m., Fort Dodge) and then perfused transcardially with sterile Hanks balanced salt solution (HBSS) at $25^{\circ} \mathrm{C}$. The paired nuclei HVc were quickly dissected out into warm tissue culture media containing $10 \%$ chicken and 15\% tetal bovine sera in 1:1 Dulbecco's modified Eagle's media: Ham's F-12 (Gibco). The medium was supplemented with 15 mM HEPES buffer, $2 \mathrm{~mm}$ L-glutamine, $10 \mathrm{~mm}$ nonessential amino acids (Gibco), $0.5 \mathrm{mg} / \mathrm{ml}$ insulin, and $40 \mathrm{U} / \mathrm{ml}$ penicillin and streptomycin. This formulation was essentially a modification of that initially described by Toran-Allerand $(1976,1978)$. Fach HVc was then minced into 25 explants, each measuring approximately $0.8 \times 0.5 \times 0.2 \mathrm{~mm}$, prepared such that each had a surface of ventricular ependyma on one of its edges. The explants were distributed into $35 \mathrm{~mm}$ Falcon dishes, each containing one glass coverslip previously coated with human plasma fibronectin (Collaborative Research). After plating, $600 \mu \mathrm{l}$ of culture medium was added to each dish. This volume incompletely immersed the explants, such that the surface tension of the medium sufficed to hold the explants down onto the coverslip; this allowed the explants to gradually adhere to the substrate layer over the following days. The prepared cultures were incubated at $37^{\circ} \mathrm{C}$ in a humidified, $5 \% \mathrm{CO}_{2} / 95 \%$ air environment and left unperturbed for at least $4 \mathrm{~d}$ before observation.

Regional controls. Both positive and negative control cultures were prepared from several brain regions besides $\mathrm{HVc}$, including areas that are both neurogenic (dorsomediocaudal neostriatum; dmcNS) and nonneurogenic (optic tectum, cerebellum, anterior hyperstriatum) in vivo (Nottebohm and Kasparian, 1986).

Immunocytochemistry. Neurons were identified immunocytochemically in the explant outgrowths, using a variety of neuron-selective or specific marker antigens. Explant outgrowths were probed for various neuronal cytoplasmic antigens, including microtubule-associated protein-1B (MAP-1B; Huber and Matus, 1984), microtubule-associated protein-2 (MAP-2; Bernhardt and Matus, 1985; Fischer et al., 1987) neuron-specific enolase (NSE; Schmechel et al., 1978, 1980), and synaptic vesicle protein-2 (SV-2; Buckley and Kelley, 1985). These cells were also examined for the presence of neuronal surface antigens, including the surface ligands for tetanus toxin (Mirsky et al., 1978), monoclonal antibody (mAb) A2B5 (Eisenbarth et al., 1979), and mAb 1A6 (Lemmon et al., 1982); the latter antibody binds avian neuronal cell adhesion molecule (N-CAM; Edelman, 1984).

MAP-2 was localized in the cultures using both rabbit polyclonal and mousc monoclonal antibodies generously provided by Dr. I. Fischer (Fischer et al., 1987). The polyclonal antiserum reacts with both the mature (2A and $2 \mathrm{~B})$ and immature (2C) forms of MAP-2 (Fischer et al., 1987), while the 2 monoclonal antibodies (I-2 and IB-2) react only with MAP-2A and 2B (Crandall and Fischer, 1989). These specificities were confirmed by immunoblotting against adult canary brain (Fischer and Goldman, unpublished data). Eight day in vitro (DIV) HVc cultures were washed several times in HBSS and fixed for 20 min at $4^{\circ} \mathrm{C}$ in $4 \%$ paraformaldehyde, followed by $10 \mathrm{~min}$ at $-20^{\circ} \mathrm{C}$ in methanol with $0.3 \%$ $\mathrm{H}_{2} \mathrm{O}_{2}$. The cultures were then washed $(5 \times 1 \mathrm{~min}$ in phosphate-buffered saline, PBS) and incubated sequentially in $10 \%$ normal goat serum (10 min, $25^{\circ} \mathrm{C}$ ), anti-MAP-2 (rabbit at $1: 200$, mouse at $1: 20$; both for 18 hr at $\left.4^{\circ} \mathrm{C}\right)$, PBS $(5 \times 1 \mathrm{~min})$, and horseradish peroxidase (HRP)-conjugated goat anti-rabbit (1:100) or anti-mouse (1:50) IgG (Fisher/Southcrn Biotech). The latter incubations were for $1 \mathrm{hr}$ at $25^{\circ} \mathrm{C}$, followed by $\mathrm{HRP}$ reaction in $0.05 \%$ diaminobenzidine (Sigma) and $0.001 \% \mathrm{H}_{2} \mathrm{O}_{2}$ for $5 \mathrm{~min}$. Cultures were then washed in PBS, dehydrated through ascending alcohols into xylene, mounted in Permount, and examined. Matched control cultures were exposed to normal rabbit serum $(1: 200)$ or mouse ascites $(1: 10)$ instead of polyclonal or monoclonal anti-MAP-2, respectively, but were otherwise treated identically.

MAP-1B was localized by a procedure similar to that used for MAP2. A rabbit anti-MAP-1B, also provided by Dr. I. Fischer, was used on methanol-fixed explant outgrowth at a dilution of $1: 100$. Overnight $4^{\circ} \mathrm{C}$ incubation in primary was followed by a $1 \mathrm{hr}$ room temperature incubation in HRP-conjugated goat anti-rabbit $\mathrm{IgG}$ at $1: 100$ and a $5 \mathrm{~min}$ reaction in $\mathrm{DAB} / \mathrm{H}_{2} \mathrm{O}_{2}$.

NSE was also identified within neurons in the HVc explant outgrowths, using the methods of Schmechel et al. (1980). Briefly, cultures were fixed for $1 \mathrm{hr}$ in a solution of $4 \%$ paraformaldehyde $/ 0.5 \%$ glutaraldehyde $/ 0.2 \%$ picric acid in acetate buffer at pH 5.2. Samples were then washed, permeabilized with $0.2 \%$ Triton X-100 in 0.1 M phosphate buffer, and incubated serially in rabbit anti-NSE (1:125, Polyscience; $96 \mathrm{hr}$ at $\left.4^{\circ} \mathrm{C}\right)$, PBS $(5 \times 1$ min washes), goat anti-rabbit IgG $(1: 25$, Cappell; $1 \mathrm{hr}$ at $\left.25^{\circ} \mathrm{C}\right)$, PBS $(3 \times 1 \mathrm{~min}$ washes), HRP-conjugated rabbitanti-peroxidase $\left(1: 50\right.$, Miles; $1 \mathrm{hr}$ at $\left.4^{\circ} \mathrm{C}\right), 0.1 \mathrm{M}$ phosphate buffer $(3 \times$

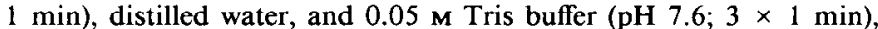
followed by HRP reaction in $0.05 \% \mathrm{DAB} / 0.001 \% \mathrm{H}_{2} \mathrm{O}_{2}$ in $0.05 \mathrm{M}$ Tris for $2 \mathrm{~min}$, followed by washing and mounting as noted above. Matched control cultures were incubated in normal rabbit serum (1:125, Cappell) rather than anti-NSE.

SV-2 was localized in 8 DIV explant outgrowths, as an additional marker of neuronal identity. Cultures were fixed in cold $4 \%$ paraformaldehyde with $0.3 \% \mathrm{H}_{2} \mathrm{O}_{2}$ for $15 \mathrm{~min}$, followed by a $5 \mathrm{~min}$ permeabilizing wash in $0.2 \%$ Triton X-100 and $15 \mathrm{~min}$ in $10 \%$ NGS. Mouse antiSV-2 IgG, provided by Dr. Kathleen Buckley, was used at 1:10; cultures were incubated in anti-SV-2 for $2 \mathrm{~d}$ at $4^{\circ} \mathrm{C}$, followed by $1 \mathrm{hr}$ in HRP. conjugated goat anti-mouse IgG $\left(1: 100 ; 25^{\circ} \mathrm{C}\right)$. All solutions were made up in $0.1 \mathrm{M}$ phosphate buffer with $1 \%$ NGS, $\mathrm{pH} 7.4$. HRP was detected by the same methods noted previously in the staining protocol for MAP-2.

Adult canary cultures were immunostained with both A2B5 and 1 A6 according to a modification of the method that Raff et al. (1983) applied to A2B5: All antibody incubations were done on living 7 DIV cultures, and reagents were made up in a diluent of $10 \%$ fetal bovine serum in Dulbecco's modified Eagle's medium. A2B5 was used at 1:14, and $1 \mathrm{~A} 6$ at 1:4. Texas red-conjugated goat anti-mouse Ig (polyvalent; Fisher/ Southern Biotech) was used at 1:40 as secondary antibody. All incuhations were carried out for $30 \mathrm{~min}$ at room temperature, and washes consisted of 3 changes of diluent. Coverslips were mounted in 3:1 glycerol-phosphate buffer with $1 \mathrm{mg} / \mathrm{ml} p$-phenylenediamine (Sigma) and were examined at $515 \mathrm{~nm}$ with a Leitz Laborlux-12 photomicroscope.

Cultures were probed for tetanus toxin binding after $8 \mathrm{DIV}$, according to previously described methods (Fields et al., 1978; Raff et al., 1979). Both tetanus toxin and rabbit antitetanus antisera were generously provided by Dr. Kay Fields. Tetanus toxin was employed as a $5 \mu \mathrm{g} / \mathrm{ml}$ solution, while antitetanus antiserum was employed at 1:100; antitoxin binding was detected by fluorescein-conjugated goat anti-rabbit IgG (1: 40, Fisher/Southern Biotech).

${ }^{3} H$-thymidine autoradiography. Five adult female canary HVcs, taken from birds ranging from 9 to 18 months of age, were exposed to ${ }^{3} \mathrm{H}$ thymidine either before or after culturing, in order to determine the time of origin of any cell outgrowth noted in vitro. Two canaries were given ${ }^{3} \mathrm{H}$-thymidine in vivo, before killing, while the HVcs derived from 3 other birds were treated with ${ }^{3} \mathrm{H}$-thymidine in vitro, after having been put into culture. All 5 birds were pretreated with testosterone silastic implants (Legan et al., 1975; Goldman and Nottebohm, 1983) for 7 $14 \mathrm{~d}$ before killing.

The 2 birds given ${ }^{3} \mathrm{H}$-thymidine in vivo were first injected with the isotope 1 week after receiving testosterone. Each bird was given 6 injections of ${ }^{3} \mathrm{H}$-thymidine, $75 \mu \mathrm{Ci}$ each (methyl- ${ }^{3} \mathrm{H}$-thymidine, $6.7 \mathrm{Ci}$ / mM aqueous, New England Nuclear), every 12 hr over a $3 \mathrm{~d}$ period. Twelve hours after the sixth and final injection, each bird was killed, and explants of its HVc and dmcNS were cultured. After 5-8 DIV, explants with significant neuronal outgrowth (at least 10 neuron-like cells per explant) were fixed in either $4 \%$ paraformaldehyde in $0.1 \mathrm{M}$ phosphate with $6 \%$ sucrose, $\mathrm{pH} 7.4$, or $2 \%$ glutaraldehyde in HBSS, $\mathrm{pH}$ 7.4. All fixatives were applied at room temperature, with subsequent postfixations carried out for at least $1 \mathrm{hr}$ at $4^{\circ} \mathrm{C}$. After fixation, the coverslips were washed in distilled water, air-dried, and affixed with the cell side up to glass slides with Permount. The mounted coverslips were dipped into Kodak NTB3 emulsion, $43^{\circ} \mathrm{C}$, and exposed in the dark for $10 \mathrm{~d}$ at $4^{\circ} \mathrm{C}$. The cultures were then developed in Kodak D 19 developer for $4 \mathrm{~min}$ at $16^{\circ} \mathrm{C}$. The autoradiographed cultures were covered with 1:1 glycerol:PBS, overlaid with a larger coverslip, and viewed by phase contrast.

The 3 birds whose $\mathrm{HVcs}$ were exposed to ${ }^{3} \mathrm{H}$-thymidine in vitro were also killed 1 week after testosterone implantation. They had not been given any ${ }^{3} \mathrm{H}$-thymidine in vivo. Instead, the medium into which their $\mathrm{HVc}$ explants were placed was supplemented with $0.2-1.0 \mu \mathrm{Ci} / \mathrm{ml}{ }^{3} \mathrm{H}$ thymidine. The explants were cultured in this ${ }^{3} \mathrm{H}$-thymidine-supplemented media for 5-8 d, after which they were fixed and autoradiographed as noted. These cultures were exposed at $4^{\circ} \mathrm{C}$ for $48 \mathrm{hr}$ before development and histological processing. A total of $377 \mathrm{HVc}$ and dmcNS explants were studied after being cultured in ${ }^{3} \mathrm{H}$-thymidine-containing media.

Combined autoradiography/immunocytochemistry. Several explant cultures, derived from birds injected with ${ }^{3} \mathrm{H}$-thymidine in vivo, were stained with rabbit anti-MAP-2, using the protocol noted above. These MAP-2-stained culture outgrowths were then air-dried and dipped into NTB-3 emulsion and incubated for 3 weeks at $4^{\circ} \mathrm{C}$. The autoradio- 
graphed cultures were then developed as described, mounted with 1:1 glycerol:PBS, and examined by Nomarski optics.

\section{Results}

Explant outgrowth

Cellular outgrowth depended on attachment of the explants to the fibronectin substrate, which generally took $48-72 \mathrm{hr}$. Cellular outgrowth from productive explants was typically apparent by the fourth DIV. Explants displaying neuronal outgrowth were first noted to yield a nonneuronal cell outgrowth composed of both morphologically undifferentiated substrate cells and ciliated ependymal cells. Most flat, nonciliated substrate cells developed into morphologically and immunochemically defined astrocytes within the following week in culture (unpublished observations). Immature neurons followed, migrating upon the underlying substrate cells. The presence of ependymal cells, as evinced by flat parvonuclear cells with actively motile cilia, was generally predictive of subsequent neuronal outgrowth. Nevertheless, neuronal outgrowth proceeded upon both ependymal and nonependymal substrate outgrowths. Neuroblasts were initially spherical and phase-bright at low power, phase-dark at higher magnification. Their central nuclei were regular, round, and had prominent nucleoli. Conversely, astrocytes and ependymal cells were flat and well apposed to the fibronectin substrate and remained phase-dark at low power.

Neurons became bipolar within 5 DIV, and developed into multipolar cells by 8 DIV (Fig. 1, $A-D$ ). Small, undifferentiated cells were rarely visible beyond this stage, and neuronal outgrowth from the explant generally ceased after the first week in vitro. Thus, neuronal outgrowth occurred largely as a unimodal wave spanning the $5 \mathrm{~d}$ period between 3 and 8 DIV. While most of these neurons died within 3 weeks after culturing, local groups of interconnected neurons were often noted within adult $\mathrm{HVc}$ outgrowths for as long as 2 months after explantation (Fig. $1 E$ ). These relatively high-density congregations frequently yielded quite complex neuronal networks.

\section{Quantification of neuronal outgrowth}

Only a minority of adult explants displayed neuronal outgrowth. Including pooled dissections, a total of $3734 \mathrm{HVc}$ and dmcNS explants were prepared, of which $2685(72 \%)$ were adherent by 4 DIV. Of these, 460 (17\%) displayed neuronal outgrowth by 7 DIV. Among differentially dissected samples, a total of $11 \%$ of adherent $\mathrm{HVc}$ explants $(82 / 718)$ and $20 \%$ of adherent dmcNS explants $(138 / 697)$ demonstrated neuronal outgrowth. The number of neurons migrating from each explant varied considerably, ranging from a few to several hundred such cells. Typically, 20-40 morphologically defined neurons appeared from each explant displaying neuronal outgrowth.

\section{Immunocytochemistry}

Antisera against MAP-1B, MAP-2, NSE, SV-2, N-CAM (1A6), and the A2B5 and tetanus toxin ligands specifically stained those cells in the explant outgrowths which had been morphologically identified as neurons (Table 1). Immunoperoxidase staining for MAP-1B, MAP-2, NSE, and SV-2 revealed clearly labeled neurons, with minimal or negligible background labeling (Fig. 2, $A-F$ ). Controls showed either a very light background staining of all cell types (rabbit serum), or no staining whatsoever (mouse ascites). Cultures exposed to antisera against MAP-2 displayed intense labeling of neuronal somata and primary fibers (Fig. 2,
Table 1. Antigens identified in new adult HVc neurons in vitro

\author{
1. Intracellular antigens \\ MAP-1B \\ MAP-2AB \\ SV-2 \\ NSE \\ 2. Surface antigens \\ N-CAM (mAb 1 A6 ligand) \\ Tetanus toxin ligand $\left(\mathrm{G}_{\mathrm{D} \mid \mathrm{b}}, \mathrm{G}_{\mathrm{T} 1}\right)$ \\ A2B5 ligand $\left(\mathrm{G}_{\mathrm{Q}}\right)$
}

Immunoreactivity for each of these antigens was detected in neurons within the cellular outgrowth from adult HVc explants, when examined between 6 and 8 DIV.

$B-D)$, the latter suggesting a dendritic localization of antigen which corresponds well to the distribution of MAP-2 in vivo. Similarly, cell body and primary fiber staining was marked for MAP-1B (Fig. 2A), NSE (Fig. 2E), and SV-2 (Fig. 2F). SV-2 was localized to both cell bodies and neurites, and no selective terminal localization of this antigen was noted. The A2B5 antibody bound to the entire surface of neurons and their fibers (Fig. 2G), as did tetanus toxin. In contrast, the 1 A6 antibody, directed against N-CAM, tended to localize to neurites, often revealing extensive neuritic networks upon the substrate cell layer (Fig. $2 H$ ).

\section{${ }^{3} \mathrm{H}$-thymidine autoradiography}

Both groups of explants, those labeled with ${ }^{3} \mathrm{H}$-thymidine in vivo and those receiving ${ }^{3} \mathrm{H}$-thymidine in vitro, showed extensive outgrowth of neurons lying on substrate cells. The 2 groups, however, showed strikingly different patterns of ${ }^{3} \mathrm{H}$-thymidine labeling.

Explants treated with ${ }^{3} \mathrm{H}$-thymidine in vitro showed no neuronal labeling. The autoradiographed cellular outgrowth from such explants, exposed for 1 weck to ${ }^{3} \mathrm{H}$-thymidine in vitro, revealed heavy glial and substrate cell labeling, consistent with persistent in vitro mitogenesis. However, under these culture conditions, neurons did not incorporate ${ }^{3} \mathrm{H}$-thymidine from the culture media (Fig. $3 A$ ). Of $226 \mathrm{HVc}$ and medial neostriatal explants raised in ${ }^{3} \mathrm{H}$-thymidine in vitro, 45 showed apparent neuronal outgrowth. Of these, a representative sample including over 100 morphologically identified neurons was autoradiographed. Among these neurons, none was seen to be ${ }^{3} \mathrm{H}$-thymidine labeled after autoradiography, while the vast majority of glial cells in the outgrowth were ${ }^{3} \mathrm{H}$-thymidine labeled.

In contrast to the results of in vitro ${ }^{3} \mathrm{H}$-thymidine exposure, cultures derived from birds that received ${ }^{3} \mathrm{H}$-thymidine in vivo yielded many labeled neurons. Figure $3 B$ shows the autoradiographed outgrowth of an 8 DIV HVc explant taken from an adult bird given ${ }^{3} \mathrm{H}$-thymidine twice daily for $3 \mathrm{~d}$ preceding its dcath. This figure displays a pair of such ${ }^{3} \mathrm{H}$-thymidinc-labcled neurons, found atop unlabeled substrate cells. Of 238 such explants plated, 41 (17\%) displayed apparent neuronal outgrowth. Most, but not all of these neurons had incorporated ${ }^{3} \mathrm{H}$-thymidine. When 7 representative outgrowths from this bird were autoradiographed, a total of 145 morphologically identified neurons were noted, of which 74 (51\%) were labeled. These neurons had incorporated ${ }^{3} \mathrm{H}$-thymidine in vivo and emigrated from the explants in vitro. 

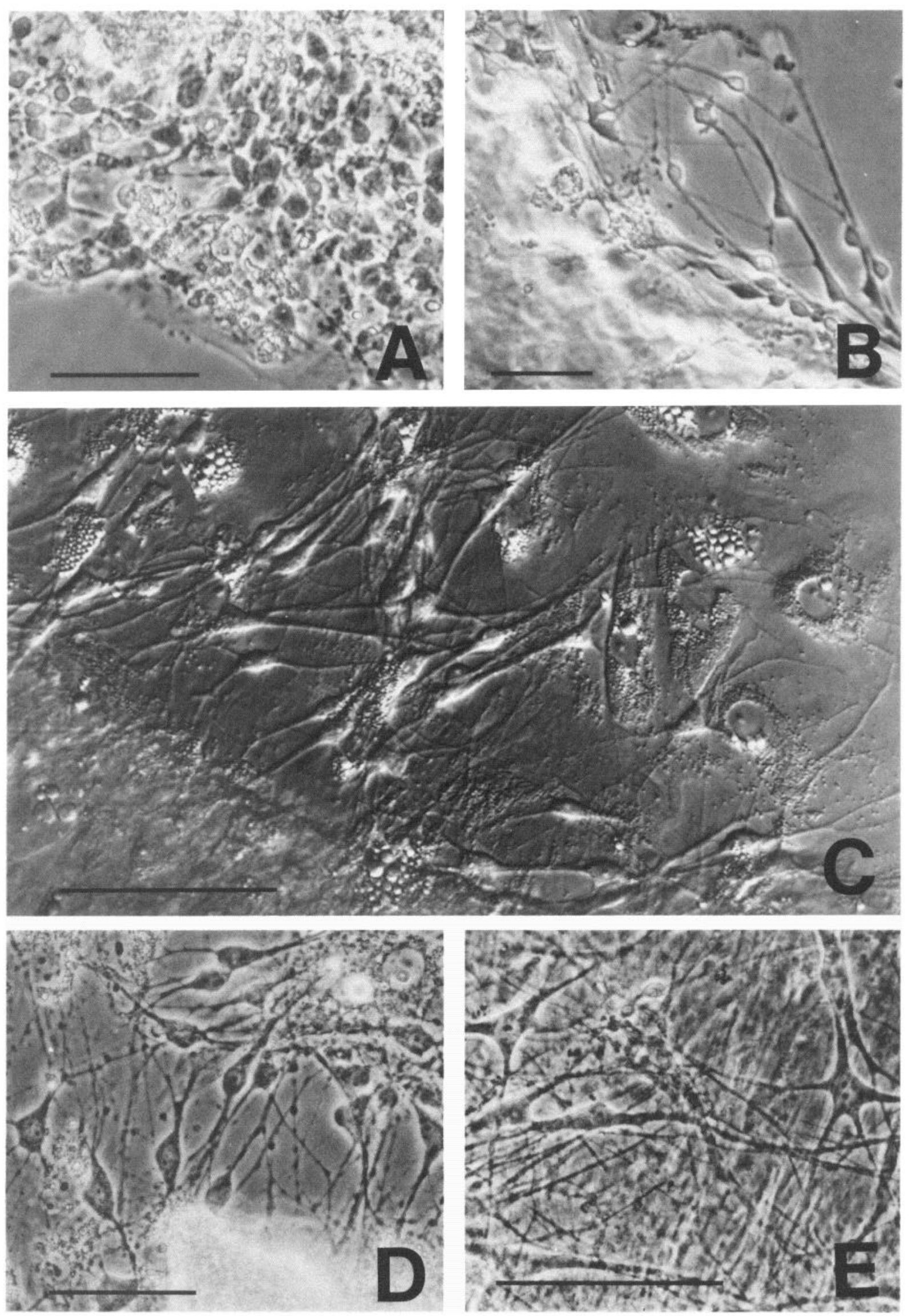


\section{Combined MAP-2 immunocytochemistry/autoradiography}

Explant outgrowths exposed to ${ }^{3} \mathrm{H}$-thymidine in vivo included neurons that labeled heavily for MAP-2. When these cultures were autoradiographed, many MAP-2-labeled neurons were noted to have incorporated ${ }^{3} \mathrm{H}$-thymidine, further indicating that neurons in the HVc explant outgrowths had been newly generated in vivo (Fig. 3C).

\section{Explants derived from nonneurogenic regions}

A total of 230 explants derived from nonneurogenic regions were also cultured (Table 2). Both forebrain and hindbrain regions were sampled; the latter included cerebellum $(n=36)$ and optic tectum $(n=51)$, while forebrain regions cultured included the lateral anterior hyperstriatum (including its nonneurogenic ventricular zone; $n=117)$, and visual wulst $(n=26)$. Explant outgrowths were scored after 7 DIV by an observer blinded as to the source of each explant. No neuron-like outgrowth was noted from any of these explants $(0 / 230)$, despite prolific glial outgrowth and observation of the cultures for up to 1 month in vitro. From the same group of 5 birds, a matched sample of 452 explants was taken from 2 highly neurogenic forebrain regions, including the HVc ventricular zone (HVc-VZ; $n=242$ ) and adjacent dmcNS ventricular zone (dmcNS-VZ; $n=210$ ). Of these, $15 \%(66 / 452)$ displayed neuron-like outgrowth within 7 DIV. The difference in neuron-like outgrowth between explants derived from neurogenic and nonneurogenic regions was examined by $\chi^{2}$ analysis, and was significant at the $p<0.001$ level.

\section{Discussion}

Neuronal outgrowth was observed from an average of $17 \%$ of explant cultures of the adult canary HVc and the adjacent dmcNS. Most of these neurons emigrated from the explants over a $4 \mathrm{~d}$ period, spanning the $3 \mathrm{rd}-6$ th DIV. These cells typically left their parent explants as immature postmitotic neurons and first developed mature neuronal morphologies within 4-5 d after leaving the explant. After $6 \mathrm{DIV}$, the number of neurons leaving the explants declined, and neuronal outgrowth ceased by the 8 th DIV. Thus, these adult HVc and enostriatal explants underwent a one-time wave of neuronal outgrowth, with no evidence of persistent in vitro neurogenesis.

\section{Immunocytochemical validation of neuronal identity}

Seven independent markers of neuronal identity, including MAP1B, MAP-2, NSE, SV-2, tetanus toxin, and mAbs $1 \mathrm{~A} 6$ and $\mathrm{A} 2 \mathrm{~B} 5$, were used to examine the antigenicity of the neuron-like cells within the adult $\mathrm{HVc}$ outgrowths. The immunochemical data supported the neuronal identity of these cells, which were consistently detected by each of these neuron-selective antibodies; in contrast, glial, fibroblastic, and ependymal labeling by these markers was absent.

The cultured neurons displayed marked immunoreactivity for the cytoskeletal antigens MAP-1B and MAP-2. MAP-2 im-

$\begin{aligned} & \text { Table 2. Neuronal outgrowth from explants of neurogenic and non- } \\
& \text { neurogenic regions of adult canary brain }\end{aligned}$
\begin{tabular}{lll} 
Total explants & $\%$ neuronal \\
Explant source & $(n=5$ birds $)$ & outgrowth \\
\hline Neurogenic regions & \\
HVc ventricular zone & $33 / 242$ & 13.6 \\
DMC neostriatal VZ & $33 / 210$ & 15.7 \\
Total & $66 / 452$ & 14.6 \\
Nonncurogenic rcgions & & \\
HA, ventricular zone & $0 / 117$ & 0 \\
HA, non-VZ & $0 / 26$ & 0 \\
Cerebellum & $0 / 36$ & 0 \\
Optic tectum & $0 / 51$ & 0 \\
Total & $0 / 230$ & 0 \\
\hline
\end{tabular}

Among adult canary brain regions cultured, neuronal outgrowth was limited to those regions displaying adult neurogenesis in vivo, including the ventricular zones of the HVc and adjacent dmcNS. DMC, dorsomediocaudal; HA, hyperstriatum anterioralis; HVc, hyperstriatum ventralis, pars caudale; $V Z$, ventricular zone.

munoreactivity was examined by both polyclonal and monoclonal immunostaining, the latter specific for MAP-2's mature, high molecular weight $2 \mathrm{~A}$ and $2 \mathrm{~B}$ forms. The latter staining was of particular importance since the low molecular weight, immature MAP-2C subunit has been reported to be expressed in young Bergmann glia (Tucker et al., 1988), while the high molecular weight forms of MAP-2 appear to be neuron-specific, both in vivo (Huber and Matus, 1984; Nunez, 1988) and in vitro (Caceres et al., 1986).

These cells were also positive for $\mathrm{A} 2 \mathrm{~B} 5,1 \mathrm{~A} 6$, and tetanus toxin ligands. The mouse mAb A2B5 (Eisenbarth et al., 1979) is believed to bind to a tetrasialoganglioside of the $G_{Q}$ class. It is relatively neuron-selective, but does cross-react with immature astrocytes and oligodendrocytes (Berg and Schachner, 1982; Schnitzer and Schachner, 1983); type 2 astrocytes continue to express the A2B5 ligand in vitro (Raff et al., 1983). Tetanus toxin, like the A2B5 antibody, binds to surface gangliosides $\left(\mathrm{G}_{\mathrm{D} / \mathrm{b}}\right.$ and $\mathrm{G}_{\mathrm{T} 1}$; Svennerholm, 1964), which are widely represented among neurons (Dimpfel et al., 1975; Fields et al., 1978; Mirsky et al., 1978). Tetanus toxin, like A2B5, may also bind to immature type 2 glial membranes (Raff et al., 1983). Nonetheless, the ventricular zone and subjacent neostriatum from which these cultures were derived would not be expected to harbor significant numbers of type 2 astrocytes, and indeed, $\mathrm{A} 2 \mathrm{~B} 5$ and tetanus toxin appeared to retain neuronal specificity in these cultures: The other neuronal antigens examined, including both surface (N-CAM) and intracellular (MAP-1B, MAP2, NSE, SV-2) antigens, uniformly localized to the same cell type as A2B5 and tetanus. In addition, the mouse mAb $1 \mathrm{~A} 6$ is specifically directed against avian N-CAM (Lemmon et al., 1982; Lagenaur and Lemmon, 1987) and binds to the same neuronal population in adult $\mathrm{HVc}$ explant outgrowths as do A2B5 and

\footnotetext{
Figure 1. Explants of adult HVc ventricular zone display neuronal outgrowth in long-term culture, with initial postmitotic neuronal migration followed by morphological and antigenic maturation. Shown are salient points of adult neuronal development in vitro. $A$, Scores of immature cells are seen emigrating from the border of an $\mathrm{HVC}_{\mathrm{c}}$ ventricular zone explant after $3 \mathrm{DIV}$. These cells are predominantly apolar and unipolar at this time. $B$, A group of neurons leaving an adult $\mathrm{HVc}$ explant after $5 \mathrm{DIV}$; neurons at this stage are pleomorphic, including immature unipolar cells as well as bi- and multipolar neurons. Most commonly, neurons tend to leave the explants upon a subjacent layer of glia and ependymal cells, as in $C$, which reveals ncurons cmigrating from an HVc explant after $6 \mathrm{DIV}$, as viewed by Hoffman modulation contrast. $D$, A similar group of neurons after 8 DIV, many of which have become multipolar; neuritic arborization proceeds rapidly at this time. $E$, A network of mature neurons and their fibers, lying on a confluent layer of substrate cells, as seen in an adult HVc outgrowth after 36 DIV. Scale bars, $50 \mu \mathrm{m}$.
} 

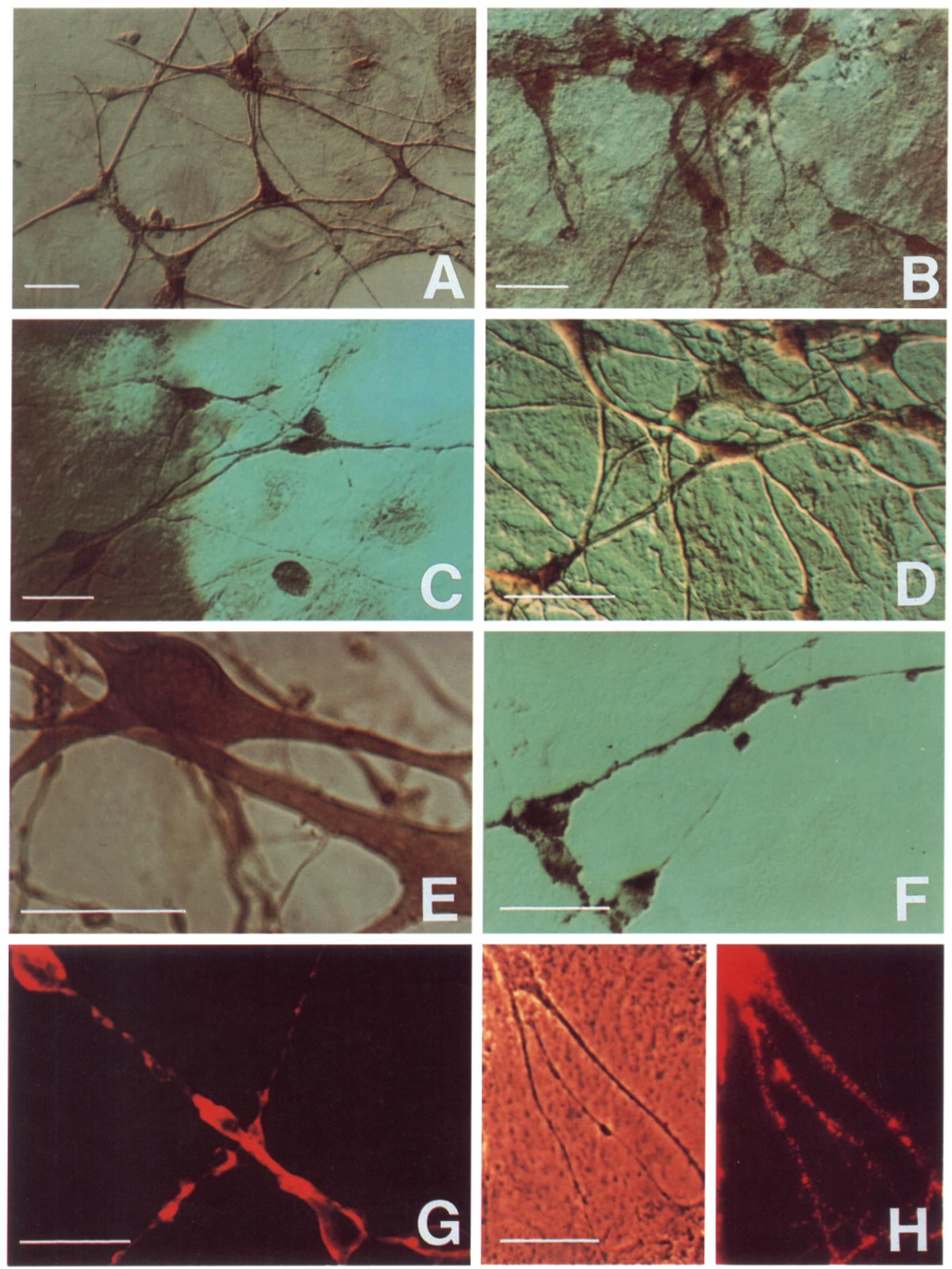
tetanus toxin, further validating their use as neuronal probes in this system. No individual antibody was relied on here for its singular value; rather, each marker was used as one element in a panel of probes which would as a group predict neuronal identity.

The immature neurons migrating from the adult $\mathrm{HVc}$ in vitro undergo morphological development according to a time course similar to that of embryonic canary neurons in culture (Goldman, 1983). However, it is not clear yet whether the ontogenetic similarities noted among devcloping neurons derived from adult and embryonic canary brain include analogous temporal patterns of neuronal antigenic expression. In this study, immunocytochemistry was performed on cultures after at least 1 week in vitro, to allow some degree of cellular and antigenic maturation prior to immunostaining.

\section{The source of the neuronal outgrowth}

Several possibilities might be advanced to explain the nature of the emigrating neurons observed in adult HVc explant culture. Conceivably, some mature neurons might have left the explant passively, upon migrating glia. Alternatively, the neurons may have differentiated in vitro from newly generated postmitotic neurons, which were migrating from the adult $\mathrm{HVc}$ ventricular zone at the time of explantation. An additional possibility is that these neurons arose through in vitro neurogenesis from dividing ventricular zone stem cells.

Among these hypotheses, it was determined that the neuronal outgrowth observed from these explants was composed largely of new neurons, created in the few days preceding killing of the bird, with subsequent neuronal maturation in vitro. In particular, the ${ }^{3} \mathrm{H}$-thymidine data indicated that neurons leaving the explants were already postmitotic once placed in culture, having undergone their terminal mitosis in the few days preceding explantation. Birds treated with ${ }^{3} \mathrm{H}$-thymidine in the days prior to killing yielded $\mathrm{HVc}$ cultures with neuronal outgrowth that was largely ${ }^{3} \mathrm{H}$-thymidine labeled. Thus a majority of the neurons leaving the adult explants had, in fact, been newly generated in vivo and were in the process of leaving the ventricular zone and embarking on parenchymal migration at the time of explantation. This synthesis may explain the unimodal time course of neuronal migration: Neuronal outgrowth may have become manifest as these newly gencratcd cells crossed the cut edge of each explant and ceased when that explant was depleted of its pool of young, migratory neurons.

Persistent neurogenesis was not observed in culture, since these neurons failed to incorporate ${ }^{3} \mathrm{H}$-thymidine from their culture medium. Thus, even though the newborn cells that emanated from these explants underwent neuronal maturation in vitro, they did so as postmitotic cells. Furthermore, those pre- mitotic neuronal precursors placed in culture appear to have become mitotically quiescent. One may suppose that these cells underwent an unscheduled terminal differentiation - most likely, but not necessarily, into neurons-or remained within their parent explants, in a morphologically undistinguishable form; alternatively, the neuronal precursor cells may have simply become nonviable in culture.

Only $51 \%$ of the neuron-like cells in the explant outgrowths were ${ }^{3} \mathrm{H}$-thymidine labeled. The unlabeled neurons might have become postmitotic prior to the first isotope injection; a longer period of ${ }^{3} \mathrm{H}$-thymidine pretreatment in vivo might have raised the proportion of labeled neurons migrating from each explant. The results might also reflect the labeling schedule employed: Using a twice daily injection schedule, some proliferating precursor cells may have evaded ${ }^{3} \mathrm{H}$-thymidine incorporation by starting and completing their terminal S-phases in the $12 \mathrm{hr}$ period separating adjacent ${ }^{3} \mathrm{H}$-thymidine injections. Indeed, in those mammalian systems in which the cytokinetics of ventricular zone proliferation have been examined, the S-phase duration has been variably described as ranging from 6-9 hr (Gracheva, 1969; Waechter and Jaensch, 1972; Schultze et al., 1974; Korr, 1980) to 10-12 hr (Lewis and Lai, 1974), depending on the gestational age of the neuroepithelium studied. These S-phase durations are all sufficiently brief that our injection schedule may have missed some proliferating neuronal precursors.

Conceivably, some unlabeled neurons might not have been new and might instead have been mature parenchymal neurons that had undergone some degree of dedifferentiation, allowing their in vitro migration and recapitulation of neuronal morphogenesis. However, since most of the neurons leaving the explants could be labeled by ${ }^{3} \mathrm{H}$-thymidine given in vivo, the relative contribution of established neurons to the explant outgrowths must have been minor.

\section{Regional specificity of neuronal outgrowth in culture}

We have shown that the neuronal outgrowth generated by explants of the adult $\mathrm{HVc}$ in vitro includes new neurons, which have arisen from the in vivo proliferation of stem cells, followed by the in vitro migration and neuronal maturation of the resultant daughter cells. A necessary corollary of these observations is that areas of the adult brain that do not show in vivo neurogenesis should not be capable of in vitro neuronal outgrowth. To test this prediction, adult explants were prepared from 4 control regions that lack significant adult neurogenesis in vivo (Nottebohm, 1985). None of the 230 control explants manifested any neuron-like outgrowth, even after a month in vitro (Table 2). In contrast, neuronal outgrowth was observed in $15 \%$ of a matched group of 452 explants taken from neurogenic re-

\footnotetext{
Figure 2. Neurons migrating from adult HVc explants express typical neuronal antigens within 1 week in vitro. $A$, An outgrowth immunoperoxidase stained for MAP-1 B, revealing the neuritic localization of this antigen. B, MAP-2-positive neurons localized within an adult $\mathrm{HVc}$ explant after 8 DIV; $C$, MAP-2-labeled neurons traversing the border of the same explant, viewed in the process of leaving the parent explant. $D$, A group of MAP-2-positive neurons in an area of dense neuronal outgrowth, as viewed by Hoffman modulation contrast after 10 DIV. E, Two neurons and their proximal neurites, after immunoperoxidase staining for neuron-specific enolase, in a 6 DIV adult HVc culture. $F$. The cellular outgrowth of another adult HVc explant after $8 \mathrm{DIV}$, stained for synaptic vesicle protein-2. Staining includes the soma as well as neurites. $G$, An adult HVc explant outgrowth stained with the mAb A2B5. This 8 DIV culture was probed with both primary and secondary (Texas red-conjugated) secondary antibodies while alive, then fixed and photographed. $H, \mathrm{~N}$-CAM immunoreactivity was also prominent on neurons of these adult $\mathrm{HVc}$ outgrowths. Corresponding phase and fluorescence-visualized images are contrasted, after staining of a living $8 \mathrm{DIV}$ culture outgrowth with mAb $1 \mathrm{A6}$ and a Texas red-conjugated secondary antibody. Neuritic staining for N-CAM predominated over that of the neuronal cell bodies in these cultures. Scale bars, $25 \mu \mathrm{m}$; except $E, 12.5 \mu \mathrm{m}$.
} 

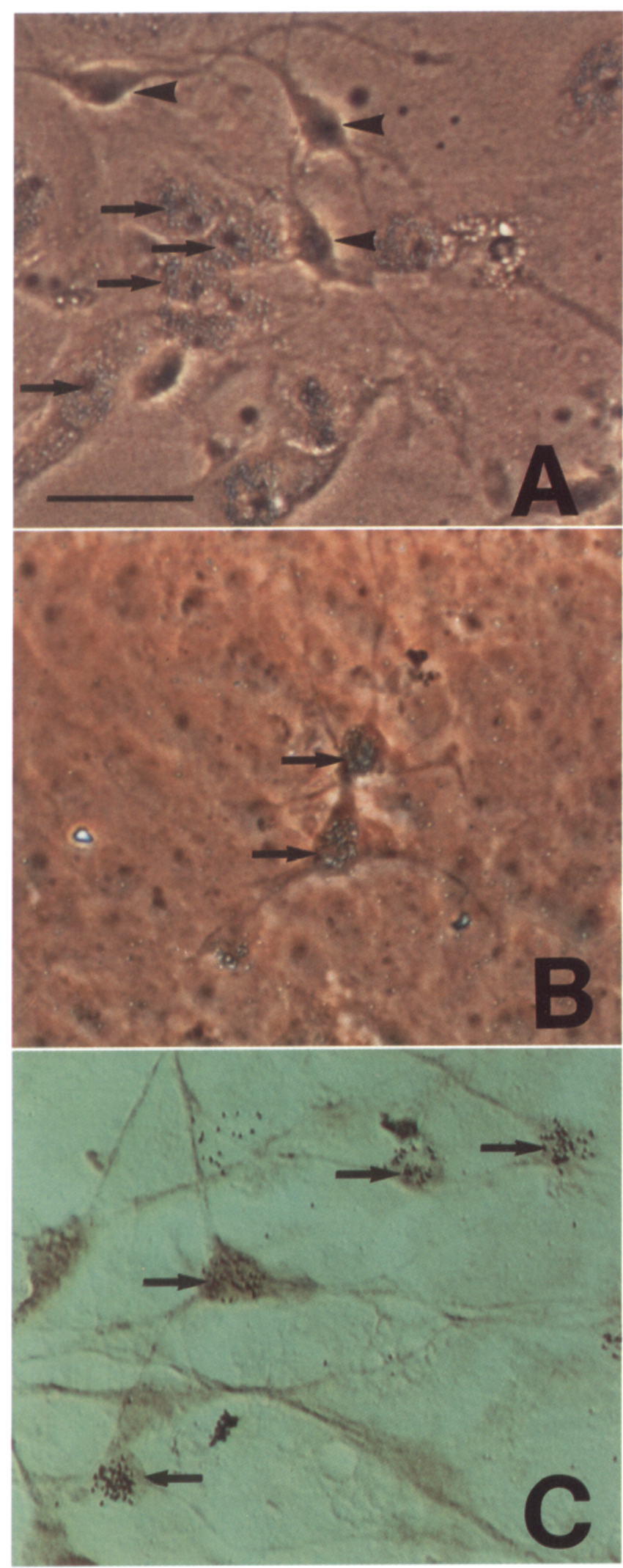

Figure 3. A, Autoradiographed outgrowth from an adult HVc explant, exposed for 1 week to ${ }^{3} \mathrm{H}$-thymidine in vitro, after which the culture was fixed. The cellular outgrowth is heavily labeled, indicating that substantial mitotic activity has occurred in vitro; however, only the substrate cells (arrows) are ${ }^{3} \mathrm{H}$-thymidine labeled. The neurons within this explant outgrowth are all unlabeled (arrowheads), indicating that they were generated prior to the bird's death. $B$, An autoradiograph of gions of the same 5 birds. Thus, in vitro neuronal outgrowth was limited solely to those areas displaying in vivo adult neurogenesis.

\section{Lack of persistent neurogenesis in vitro}

We have not entirely excluded the possibility of persistent in vitro neurogenesis in these explants. New neurons could have continued to arise in culture, but either failed to leave the explant ventricular zone or failed to survive the week in vitro prior to fixation and autoradiography. An analysis of cells generated in vitro and remaining within the confines of the explant is now underway. Nevertheless, it is likely that under the culture conditions employed here, which included a high serum medium and fibronectin substrate, mitotic activity within the adult $\mathrm{HVc}$ neuronal precursor pool ceased, even while postmitotic neuronal migration and maturation proceeded apace. Similar cessation of in vitro neuronal production by cells known to be mitogenic in vivo has been described in other neurogenic systems (e.g., Calof and Chikaraishi, 1989). Although several authors have described persistent in vitro neurogenesis under specific culture conditions (e.g., Kriegstein and Dichter, 1984; Anderson and Waxman, 1985), it is clear that the permissive factors for ex vivo neuronal production are poorly understood. The facilitation of persistent neurogenesis in cultures of the adult songbird brain may require a defined, serum-depleted medium, free of potential antimitotic or differentiation factors; alternatively, in vitro neurogenesis may require supplementation by mitogenic serum or substrate factors not present in our cultures. Accordingly, complementary in vitro studies are now underway examining the effects of diverse regulatory factors on the proliferation, development, and survival of both the neuronal precursor cells and newly generated neurons of the adult songbird forebrain.

\section{References}

Alvarez-Buyulla A, Nottebohm F (1988) Migration of young neurons in adult avian brain. Nature 335:353-355.

Alvarez-Buyulla A, Theelan M, Nottebohm F (1988) Birth of projection neurons in the higher vocal center of the canary forebrain before, during, and after song learning. Proc Natl Acad Sci USA 85:87228726.

Anderson M, Waxman S (1985) Neurogenesis in tissue cultures of adult teleost spinal cord. Dev Brain Res 20:203-212.

Berg G, Schachner M (1982) Electron microscopic localization of A2B5 cell surface antigen in monolayer cultures of murine cerebellum. Cell Tissue Res 224:637-645.

Bernhardt R, Matus A (1985) Differences in the developmental patterns of three microtubule associated proteins in the rat cerebellum. J Neurosci 5:977-991.

Buckley K, Kelley R (1985) Identification of a transmembrane glycoprotein specific for secretory vesicles of neural and endocrine cells. J Cell Biol 100:1284-1294.

\footnotetext{
an HVc outgrowth after 6 DIV. This explant was taken from an adult female that had been injected with ${ }^{3} \mathrm{H}$-thymidine in vivo, twice daily during the $3 \mathrm{~d}$ preceding killing and culture. In sharp contrast to $A$, few if any substrate cells are labeled, while two neurons (arrows) have incorporated ${ }^{3} \mathrm{H}$-thymidine, as revealed by the silver grains overlying their nuclei. $C$, A Nomarski image of an adult HVc explant outgrowth subjected to combined MAP-2 immunocytochemistry and ${ }^{3} \mathrm{H}$-thymidine autoradiography. This 8 DIV culture was derived from an adult female canary treated with ${ }^{3} \mathrm{H}$-thymidine twice daily for $3 \mathrm{~d}$ prior to killing. At least 4 MAP-2-positive neurons in this field are labeled with ${ }^{3} \mathrm{H}$ thymidine (arrows) and thus were newly generated in vivo. Scale bar, $50 \mu \mathrm{m}$.
} 
Burd GD, Nottebohm F (1985) Ultrastructural characterization of synaptic terminals formed on newly generated neurons in a song control nucleus of the adult canary forebrain. J Comp Neurol 240: 143-152.

Caceres A, Banker G, Binder L (1986) Immunocytochemical localization of tubulin and MAP-2 during the development of hippocampal neurons in culture. J Neurosci 6:714-722.

Calof A, Chikaraishi D (1989) Analysis of neurogenesis in a mammalian ncurocpithclium: proliferation and differentiation of an olfactory neuron precursor in vitro. Neuron 3:115-127.

Costero I, Pomerat C (1951) Cultivation of neurons from the adult human cerebral and cerebellar cortex. Am J Anat 89:405-467.

Crandall J, Fischer I (1989) Developmental regulation of MAP2 expression in regions of mouse brain (in press).

de Boni U, Seger M, Scott J, Crapper D (1976) Neuron culture from adult goldfish. J Neurobiol 7:495-512.

Dimpfel W. Neale J, Habermann E (1975) ${ }^{125}$ I-labeled tetanus toxin as a neuronal marker in tissue cultures derived from embryonic CNS. Naunya-Schmiedelbergs Arch Pathol Pharmacol 290:329-333.

Edelman $G$ (1984) Modulation of cell adhesion during induction, histogenesis, and perinatal development of the nervous system. Annu Rev Neurosci 7:339-377.

Eisenbarth G, Walsh R, Nirenberg M (1979) Monoclonal antibody to a plasma membrane antigen of neurons. Proc Natl Acad Sci USA 76: 4913-4917.

Fields KL, Brockes J, Mirsky R, Wendon L (1978) Cell surface markers for distinguishing different types of rat dorsal root ganglion cells in culture. Cell 14:43-51

Fischer I, Kosik K, Sapirstein V (1987) Heterogeneity of microtubuleassociated protein (MAP2) in vertebrate brains. Brain Res 436:3948.

Geiger $R$ (1958) Subcultures of adult mammalian cortex in vitro. Exp Cell Res 14:541-566.

Goldman S (1983) Neuronal production, migration and differentiation in the adult avian brain, in vivo and in vitro. Doctoral dissertation, The Rockefeller University, New York.

Goldman S, Clarke W (1989) In vitro antigenic and ultrastructural characterization of neuroblasts derived from a neurogenic region of the adult canary brain. Soc Neurosci Abstr 15:962.

Goldman S, Diacumakos E (1984) In vitro neuroplasticity of the adult canary forebrain. Soc Neurosci Abstr 10:664.

Goldman S, Nottebohm F (1982) Ependymal neurogenesis in adult female canaries. Soc Neurosci Abstr 8:140.

Goldman S, Nottebohm F (1983) Neuronal production, migration and differentiation in a vocal control nucleus of the adult female canary brain. Proc Natl Acad Sci USA 80:2390-2394.

Goldman S, Nottebohm F, Bradley G, Diacumakos E (1982) Long term culture of the vocal control nucleus, $\mathrm{HVc}$, of both embryonic and adult canary brain. J Cell Biol 95:42a.

Gracheva N (1969) Autoradiographic investigation of proliferative activity of the rat brain subependymal cells. Tsitologiya 11:15211527.

Hogue $M$ (1953) A study of adult human brain cells in tissue culture. Am J Anat 93:397-427.

Huber G, Matus A (1984) Immunocytochemical localization of microtubule associated protein-1 in rat cerebellum using monoclonal antibodies. J Cell Biol 98:777-781.

Kiernan J, Petit D (1971) Organ culture of central nervous system of the adult rat. Exp Neurol 32:111-120.

Kim S, Warren K, Kalia M (1979) Tissue culture of adult human neurons. Neurosci Lett 11:137-141.

Korr $H$ (1980) Proliferation of different cell types in the brain. Adv Anat Embryol Cell Biol 61:1-72.
Kriegstein A, Dichter M (1984) Neuron generation of dissociated cell cultures from fetal rat cerebral cortex. Brain Res 295:184-189.

Legan J, Coon G, Karsch F (1975) Role of estrogen as initiator of daily LH surges in the ovariectomized rat. Endocrinology 96:50-54.

Lagenaur C, Lemmon V (1987) An Ll-like molecule, the 8D9 antigen, is a potent substrate for neurite extension. Proc Natl Acad Sci USA 84:7753-7757.

Lemmon V, Starvos E, Perry H, Gottlieb D (1982) A monoclonal antibody that binds to the surface of chick brain cells and myotubes: cell selectivity and properties of the antigen. Dev Brain Res 11:191197.

Lewis P, Lai M (1974) Cell generation in the subependymal layer of the rat brain during the early postnatal period. Brain Res 76:520 525 .

Messing A, Kim S (1979) Long term culture of adult mammalian CNS neurons. Exp Neurol 65:293-300.

Mirsky R, Wendon L, Black P, Stolkin C, Bray D (1978) Tetanus toxin: a cell surface marker for neurones in culture. Brain Res 148: 251-259.

Nottebohm F (1985) Birdsong as a model to study brain processes related to learning. Condor 86:227-236.

Nottebohm F, Kasparian S (1986) Widespread labelling of avian forebrain neurons after systemic injections of ${ }^{3} \mathrm{H}$-thymidine in adulthood. Soc Neurosci Abstr 9:380.

Nunez J (1988) Immature and mature variants of MAP2 and tau proteins and neuronal plasticity. Trends Neurosci 11:477-479.

Paton J, Nottebohm F (1984) Neurons generated in the adult brain are recruited into functional circuits. Science 225:1046-1048.

Paton J, O'Louglin B, Nottebohm F (1985) Cells born in adult canary forebrain are local interneurons. J Neurosci 5:3088-3093.

Raff M, Fields K, Hakomori S-Q, Mirsky R, Pruss R, Winter J (1979) Cell type specific markers for distinguishing and studying neurons and the major classes of glial cells in culture. Brain Res 174:283-308.

Raff M, Abney E, Cohen J, Lindsay R, Noble M (1983) Two types of astrocytes in cultures of developing rat white matter: differences in morphology, surface gangliosides, and growth characteristics. J Neurosci 3:1289-1300.

Schmechel D, Marangos P, Zis A, Brightman M, Goodwin F (1978) The brain enolases as specific markers of neuronal and glial cells. Science 199:313-315.

Schmechel D, Brightman M, Barker J (1980) Localization of neuron specific enolase in mouse spinal neurons grown in tissue culture. Brain Res 181:391-400.

Schnitzer J, Schachner M (1983) Cell type specificity of a neural cell surface antigen recognized by the monoclonal antibody A2B5. Cell Tissue Res 224:625-636.

Schultze B, Nowak B, Maurer W (1974) Cycle times of the neural epithelial cells of various types of neuron in the rat. An autoradiographic study. J Comp Neurol 158:207-218.

Svennerholm L (1964) The gangliosides. J Lipid Res 5:145-155.

Toran-Allerand CD (1976) Sex steroids and the development of the newborn mouse hypothalamus and preoptic area in vitro. Brain Res $106: 407-412$.

Toran-Allerand $\mathrm{CD}$ (1978) The luteinizing hormone-releasing hormone neuron in cultures of the newborn mouse hypothalamus and preoptic area: ontogenetic aspects and responses to steroid. Brain Res 149:257-265.

Tucker R, Binder L, Matus A (1988) Neuronal microtubule associated proteins in the embryonic avian spinal cord. J Comp Neurol 271:4455.

Waechter R, Jaensch B (1972) Generation time of the matrix cells during embryonic brain development: an autoradiographic study in rats. Brain Res 46:235-250. 